\title{
THE METAPHYSICS OF RESPONSIBLE BELIEVING
}

\author{
DAVID HuNTER \\ Ryerson University \\ Department of Philosophy \\ Canada \\ david.hunter@ryerson.ca
}

\begin{abstract}
Article info
CDD: 128.2

Received: 03.08.2018; Accepted: 17.08.2018

DOI: http://dx.doi.org/10.1590/0100-6045.2018.V41N4.DH
\end{abstract}

\section{Keywords:}

Belief

Agency

Responsibility

Metaphysics of mental states

Abstract: Contemporary philosophy of mind has tended to make the believer disappear. In response, Matt Boyle and Pamela Hieronymi have argued that believing is an act or activity, not a mental state. I argue that this response fails to fully critique contemporary accounts of believing. Such accounts assume that (i) states of believing are particulars; (ii) with semantic properties; (iii) that we attend to in reflection and act on in inference; and (iv) with a rich causal life of their own. Together, these assumptions leave no room for the believer in an account of believing. But these assumptions are not entailed by the idea that believing is a mental state. Careful reflection on other kinds of states helps us see how to put the believer back in the heart of our account of believing. 


\section{THE DISAPPEARING BELIEVER}

A good deal of contemporary philosophy of mind grants mental states like believing and desiring a life of their own, and it is a very rich life indeed. Mental states are treated as individuals, with the power to move arms and legs, as the primary subjects of praise and blame, with a variety of semantic properties, and, sometimes, even psychic and teleological ones. All of this has made the subjects of mental states - the believers and desirersdisappear from view. And this, in turn, has made the characteristic forms of responsibility we have in believing and desiring seem mysterious.

In response, some theorists have abandoned the idea that believing is a mental state at all. Matt Boyle and Pamela Hieronymi have argued that to understand mental responsibility we need to think of believing as an act or activity. Here is how Boyle describes the responsibility characteristic of believing.

We expect... subjects, not merely to hold various beliefs, but to be cognizant of what beliefs they hold; and we expect then, nor merely to have their beliefs regulated by the presence or absence of grounds, but to be able themselves to discuss the grounds, to be able themselves to discuss the grounds on which they hold the beliefs they do.... We do not merely suppose that cognitively mature human beings can, in the normal case, give expert testimony on what they believe and why. We treat them as in some sense in charge of what they believe and why, not merely specially knowledgeable about these topics. (Boyle 2009, 122-3) 
One idea here is that believing involves self-knowledge. If Jones believes that the 504 streetcar stops at Garden Avenue, then Jones knows that she believes it. What is more, Jones knows something about why she believes it, at least in the sense that if we ask her why she believes it, she will be ready with an answer. A second idea is that believing involves self-determination. People are able to make up their own minds and are held to account when they do and are expected to change their minds when doing so is called for. We are, as Boyle puts it, in some important sense, in charge of the fact that we believe what we do. The main challenge facing a theory of epistemic responsibility is to flesh out what this being-in-charge comes to.

Boyle and Hieronymi claim that we cannot understand it if we think of believing as a mental state. Instead, they suggest, we need to think of it as a special sort of act or an activity, one that is not intentional or voluntary. According to Boyle, 'belief (i)s an enduring, non-occurrent act of assenting to a proposition. (Boyle 2011, 142, n. 31). Hieronymi suggests that "believing is an activity done for reasons, though not something that can be completed or finished". (Hieronymi, 2009, 174) I find much to value in their positive proposals about mental responsibility. But I think their diagnosis of the problem they are responding to has not been radical enough. Contemporary philosophy of mind has made epistemic responsibility seem mysterious, not because it has overlooked the ways that believing is like an action, but because its standard conception of mental states leaves no room for the subjects of belief and desire. To understand mental responsibility we need to bring the believer back into focus, by showing the errors in the standard story about the metaphysics of believing.

My goals here are very modest. I will use the work of Boyle and Hieronymi as foils to help sketch an alternative metaphysics of mental states, and of believing in particular, one that avoids errors in the standard conception. I won't 
defend every detail of my sketch, and much of my discussion will be at a general and abstract level. ${ }^{1}$ I want to bring out how their embrace of an active conception of believing rests on an incomplete critique of the standard view. To fully understand epistemic responsibility we need to get clearer, not just on the metaphysics of mental states in general, but also on those of believing and desiring themselves. ${ }^{2}$ This large project is well beyond the scope of one essay. But I hope that a broad-brush sketch of an alternative view of the nature of mental states can be of some help.

\section{FOUR ASSUMPTIONS}

In critiquing the state view of believing, Boyle and Hieronymi rely on a caricature of it, one that no proponent of the state view would explicitly accept. But the caricature is helpful in shining a clear light on the assumptions that inform the standard view and, I want to suggest, in revealing the ways Boyle and Hieronymi's rejection of it has not been radical enough.

As Boyle sees it, on the state view

[i]f we exercise agential control over our beliefs, this must consist in our performing occurrent acts of judgment which give rise to new beliefs, or cause extant beliefs to be

\footnotetext{
1 The ideas sketched here are developed fully in a book manuscript, currently in preparation. Several relevant chapters are in the list of references.

2 I discuss the self-knowledge involved in believing in (Hunter 2011) and (Hunter 2018a).
} 
modified. Beliefs can at most "store" the results of such acts. So a person's agency can get no nearer to her beliefs than to touch them at their edges, so to speak. (Boyle, 2009, 121)

While the state view of belief can allow acts of judging or affirming, their role (according to Boyle) must be limited to causing or modifying states of belief. The believing itself could not be anything active. But this, he charges, distorts our relation to our beliefs.

[The state view] appears to leave us responsible only for looking after our beliefs, in something like the way I may be responsible for looking after my bicycle. I have chosen to acquire this bicycle, and I can take steps to ensure that it is in good condition, that it is not left in a bad spot, etc. I am responsible for it as something I can assess and act upon, something in my care. I am not responsible for it, however, in the way I am responsible for my own intentional actions. My actions stand in a more intimate relation to me: they are not things I control by acting on them; they are my doings themselves. (Boyle, 2009, 121; italics in original)

The image of 'beliefs' as stored products of judgment also appears in Hieronymi's critique of the state view.

My beliefs do not sit in my mind as last week's lecture sits on my hard drive, recording what I once thought. My beliefs are rather my present, ongoing take on what is so. When I 
revise a belief, I do not—or, typically I do not-notice that it no longer says what I think and then do something to change it. Rather, as I think about what is so, my beliefs therein change. Moreover, the current effect of my beliefs on my thought and behavior is not the indirect consequence of some past activity of mine, via standing dispositions, an effect which I might have once predicted, when I formed the disposition, and might now notice and perhaps do something to change. My beliefs are not like the "out of office reply" feature that I set up for my e-mail account: they are not something I create and then allow to affect things on my behalf. (Hieronymi, 2009, 176; italics in original)

Boyle and Hieronymi are knowingly offering a caricature of the state view. No one thinks that beliefs are like files on hard drives or recordings on machines, or that our relation to them is like our relation to our bicycles. Everybody should agree that believing is not like that. But the purpose of the caricature is to force us to say how believing is different.

As I see it, the standard view of states of believing assumes that they (i) are particulars in the same ontological category as bikes and geraniums; (ii) are bearers of semantic and normative properties; (iii) are entities we attend to and act on in theoretical reasoning; (iv) and are causes or causal powers. These assumptions are loosely linked together by the thought that believing is a state a person has, or that is inside a person, as opposed to a state a person is in. Together they picture the believer as fundamentally passive in representing the world, in making up her mind about it, and in acting on what she believes. The believer has 
disappeared from the story about the nature and role of believing.

\section{STATES OF BELIEVING AS PARTICULARS}

The first assumption is the most important, and the most deeply entrenched. By treating states of believing as entities in their own right, by bypostasizing them, the standard view effectively removes the believer from focus. States of believing become entities a person has or entities that are inside a person. Boyle and Hieronymi are right to mock the idea that they are like bicycles, house plants, and computer files, but their critique does not go far enough. (As we will see, they retain the assumption, if only tacitly.) It is not just that believing is a different kind of individual. The mistake is assuming that they are such things as particular states of believing at all. Indeed, this mistake is at the very heart of the case of the disappearing subject.

To see this mistake, we need to appreciate the difference between two kinds of properties: sortals and qualities. ${ }^{3}$ The properties of being a chair and of being tall differ in many ways, but one difference is reflected in the linguistic fact that 'chair' allows a plural, while 'tall' does not. We can speak of the chairs in the room, we can count them, and we can sensibly ask whether the chairs that are here now are the ones that were here this morning. Maybe some evil demon has been subtly substituting them every five minutes without our noticing it. In grasping the property of being a chair we grasp how to consider and answer questions like this. But we cannot count the talls in the

3 What I say here is deeply indebted to the important work (Marcus 2006) and (Marcus 2009). I develop the idea that beliefs are states a person is in and not states inside a person in (Hunter 2001). Similar views are in (Kenny 1989) and (Steward 1997). 
room. We need instead to speak of the tall things, or tall people, or tall pieces of furniture, or etc. in the room. Likewise, if Jones is tall, it makes no sense to ask whether his being tall today is the same as his being tall yesterday. The property of being a chair is a sortal and is instantiated in a particular, whereas the property of being tall is a quality and is exemplified in a particular.

Physical properties such as being tall and being short are qualities and not sortals. Some psychological properties such as being happy and being in mourning are not sortals. Anthony Kenny drew attention to this by noting that it makes no sense to ask how many senses of humour Oliver Cromwell might have had. The mistake is not in thinking that he might have had three or four, but in thinking that having a sense of humour is a sortal property. (Kenny 1989, 72) Importantly, ability properties are not sortals. We can count the people in a room who are able to speak Portuguese or who can play piano. Each of them has the property of being able to speak Portuguese or play the piano. But there is no such thing as counting the havings of those abilities. If there were, then it would make sense to ask whether Marco's ability to speak Portuguese is the very one he had yesterday, or whether perhaps his ability has been replaced from one moment to the next without our noticing, or whether he might in fact have three abilities to speak Portuguese.

Now consider belief properties, such as the property of believing that the 504 streetcar stops at Garden Avenue. If it is a quality and not a sortal then it should make no sense to count cases of it. And sure enough the idea of counting believings is odd. Like all of us, Jones believes many things, but how many believings by her are there? We might try counting the things she believes, but counting things believed is not the same as counting believings. Does she have only one believing of that proposition, and if so, is that a merely contingent fact about her so that she might 
conceivably have had two believings of it, in the way she has two lungs? Is her believing of it now numerically identical to her believing of it five minutes ago, or might an evil demon be surreptitiously replacing her believing of it (along with her left lung) every five minutes? These questions are odd, but not because their answers are obvious; they are odd because it is not at all clear how to begin answering them.

It is illuminating to compare believing and owning. If Sarah owns 20 books, she has 20 possessions, but how many possessings by her are there? Is there one possessing for each book, and so 20 possessings? Or is there one possessing of 20 books? Is her state of owning $W$ ar and Peace the very same state she was in yesterday, or has it perhaps been subtly switched by an evil demon? Could it be she has two or twenty-five ownings of a single book? Our ordinary understanding of ownership, in contrast to our understanding of such sortal properties as being a chair and being a bicycle, does not yield answers to these questions. This, together with the fact that the plural 'possessings' sounds so odd, is reason, I think, to resist saying there are any token possessings at all. Of course, this is perfectly compatible with saying that Sarah owns thousands of things. What we are denying is the odd idea that owning thousands of things involves being in thousands of states of owning. It seems to me that in these respects believing something is the same as owning something. Belief properties are qualities and not sortals. If so, then there are no such things as token beliefs. It is not just that believing would be a different kind of particular than bicycles and geraniums. States of believing would not be particulars at all. 


\section{BELIEVING AS AN ACT OR ACTIVITY: A CRITIQUE}

Boyle and Hieronymi both seem, at least tacitly, to share the assumption that belief properties are sortals. This is reflected in their frequent use of the plural 'beliefs'. Here is a passage from Hieronymi.

My beliefs do not sit in my mind as last week's lecture sits on my hard drive, recording what I once thought. My beliefs are rather my present, ongoing take on what is so. (Hieronymi, 2009, 176)

What she is objecting to in the first sentence is the idea that beliefs are a certain type of particular, no the very idea that they are particulars. Here is a passage from Boyle.

We expect... subjects, not merely to hold various beliefs, but to be cognizant of what beliefs they hold; and we expect them, not merely to have their beliefs regulated by the presence or absence of grounds, but to be able themselves to discuss the grounds on which they hold the beliefs they do. (Boyle 2009, 123)

And in noting the similarities between practical and epistemic agency, he says the following.

If our relation to our own beliefs is structurally comparable to our relation to our intentional actions, and if we have intrinsic control over the latter, then we should expect that the control we exercise over our beliefs is also intrinsic. (op. cit. 143)

In its most common usage, the plural noun 'beliefs' refers to what a person believes, standardly considered to be 
a proposition. Propositions are objects and so are countable. But in these passages, Hieronymi and Boyle cannot have propositions in mind. For propositions are not a person's 'take' on the world and we do not exercise control over propositions. They must mean by 'beliefs', not what is believed, but rather the believing of a thing. So they have in mind particular states of believing conceived of as in the same ontological category as bicycles and germaniums but somehow more intimately related to believers. What is more, their leading idea-that people can be related to belief tokens in something like the way they can be related to actions-also reveals their (tacit) commitment to the first assumption, since actions are particulars. We can count the number of times Jones took a book off his shelf, turned on the light, or rode his bike. The idea that believing might be a kind of act can seem natural, or anyway a live option, only if one assumes that belief properties are sortals. But if belief properties are qualities and not sortals, then their proposal to model believing on acting breaks down.

In his critique of Boyle, Matthew Chrisman sees a category mistake. ${ }^{4} \mathrm{He}$ notes that investigating a subject matter is an activity as is maintaining one's system of beliefs. But he worries that Boyle is tacitly confusing believing with these activities.

[1] t seems to me that, in talking about "active states", Boyle is either tacitly changing the

4 Kieran Setiya (2008) lodges a similar complaint against Hieronymi's view. He says she conflates the metaphysical categories of states and events, in particular the distinction between believing something and forming a belief. In reply, she says she finds the distinction suspicious, and is seeking a way to think about mental phenomena that is not bound by it. (Hieronymi 2009, 173) 
focus to activities that are necessary for (but not identical to) being in a belief state, or appealing to an ad hoc metaphysical category in a way that obscures rather than explains how we exercise agency with respect to our belief states. Perhaps I am placing too much weight on Boyle's suggestion that there are 'states which are acts'; even if we reject this rhetoric perhaps we should still recognize a distinction between the energetic states that are themselves 'enduring' actualizations or manifestations of our human capacities, and so in that sense active-e.g., being happy, being in love, etc.- - and kinetic' processes that have a non-energetic state as their endpointe.g., getting a haircut, digesting food. Even so...conceiving of belief as an 'energetic' state within this schema doesn't really explain why we normatively evaluate our beliefs themselves in addition to the processes by which we get into these states. (Chrisman 2016, 11; italics added)

Chrisman is in effect framing a dilemma. If, on one hand, Boyle is invoking a metaphysical distinction that lacks independent rationale, that of an energetic state, then Boyle's account is 'ad hoc' and so does not really illuminate epistemic agency. But if, on the other, Boyle is proposing that we model active belief on active processes, then since we are not responsible for all such processes (e.g., digestion), then his proposal fails to illuminate epistemic agency.

I worry that Boyle's proposal also risks begging the question by modeling active belief on speech acts. He says that 'belief (i)s an enduring, non-occurrent act of assenting to a proposition. (Boyle 2011, 142, n. 31, italics added). 
There is a speech act of assenting to a proposition, but it is something one can do voluntarily and intentionally. Jones can willingly assent to a proposition in order to please her mother. But this is not what Boyle has in mind in saying that believing is an act of assenting, since he denies that believing is voluntary or intentional. So by relying on the notion of assent in characterizing active belief, he runs some risk of begging the question.

He would do better with a more neutral characterization of believing. One traditional idea is that believing is a sort of rational capacity. This is often paired with an idea about knowledge: to know that $\mathrm{p}$ is to be able to do, think, or feel something in light of the fact that p. Believing differs from knowing in that one can be mistaken in believing something, so believing cannot be a capacity to act in light of a fact. The natural suggestion is that to believe that $p$ is to be able to do, feel or think something in light of a putative (or possible) fact that p. 5 This rough idea can be developed in different ways, but it is neutral on the question whether believing requires the ability to speak, and on whether, even if it does, speech acts have a privileged place in its manifestation. I take it that if responsible believing is possible, then it is possible even if believing is a rational capacity.

A final and more pressing worry about Boyle's proposal, perhaps suggested in the final lines from Chrisman, is that Boyle's proposal risks simply shifting the problem from the philosophy of mind to the philosophy of action. Boyle's proposal is that we should think of believing, not as a state, but as an act of a certain kind, with the believer as the agent of the act. But, as Chrisman notes, a person is not the agent of every process that occurs in her. So merely counting believing as an activity or a process won't itself entail that the believer is agent of that process. Moreover, as others

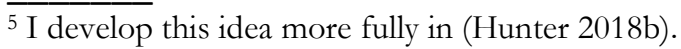


have complained, contemporary philosophy of action has also made the agent disappear. It treats actions as eventstypically bodily movements-having their own causal powers. Nothing will have been gained by thinking of believing as an act if acts themselves are agentless. To recover epistemic responsibility, Boyle must not only develop the idea that believing is an act, he must also show that believers are active in believing. He must show that believing is relevantly different from, say, digestion. Exactly parallel points apply to Hieronymi's proposal that believing is an "activity done for reasons". Their strategy for understanding mental responsibility merely shifts the problem from the philosophy of mind to the philosophy of action.

\section{ARE STATES OF BELIEVING TRUE?}

Let us return to our four assumptions. The first-that states of believing are particulars-goes hand-in-hand with the second-that they have semantic properties. I have in mind the idea that beliefs are true or false. This encourages the thought that believers have representations inside of them, entities that by their very nature have representational properties and are correct or incorrect, as if in believing the believer is representationally passive. To bring the believer back into focus, we need to recover the idea that for a person to believe something is for her to be right or wrong about something, not for some entity inside of her to be right or wrong.

Here are representative statements of the idea that states of believing are true or false.

As they are conceived and spoken of in our folk theory, both beliefs and the objects of 
beliefs can have semantic properties. Thus we may say either

Maggie's belief is true.

or

What Maggie believes is true.

However, the truth value of a belief must be the same as the truth value of the object of the belief. Thus common sense finds nothing but paradox in a claim like

John's belief is true, though what he believes is false. (Stich 1985,

Belief is... a propositional attitude. But if belief states are relations to propositions, they are automatically truth-evaluable. They are true if the proposition that is their object is true. (Braddon-Mitchell and Jackson 1996, 177)

And he idea that beliefs are true or false is central to a variety of philosophical projects. It is commonly held that belief "aims at truth" (Williams, 1973, 137) and that explaining how states of believing get their propositional 'content' is "the basic question about mental content" (Kim, 1996, 184). But not all theorists accept the idea that states of believing are true or false.

Some say that "truth is primarily a property of beliefs." But it may be doubted whether the expression "a true belief" is at all common outside philosophy and theology: and it seems 
clear that a man is said to hold a true belief when and in the sense that he believes (in) something which is true, or believes that something which is true is true. Moreover if, as some also say, a belief is "of the nature of a picture," then it is of the nature of what cannot be true, though it may be, for example, faithful. (Austin 1979, 112; italics added)

Denying that states of believing are true or false is compatible with recognising a distinctive link between belief and truth: whether a person is right or wrong in believing something depends on whether a certain proposition is true or false. If Jones believes that the 504 streetcar stops at Garden, then she is right depending on whether the proposition that the 504 stops there is true. 6

The idea that states of believing are true or false rests, so far as I can see, in a failure to distinguish propositions, belief facts and belief properties.

1. The proposition that the 504 stops at Garden

2. The fact of Jones' believing that the 504 stops at Garden

3. The property of believing that the 504 stops at Garden

A proposition is an abstract particular that is true or false, or anyway can be true or false, and that has truth conditions essentially. The second item is the fact that consists in Jones's believing that the 504 stops at Garden. I

\footnotetext{
${ }^{6}$ Arthur Collins argued that this sort of sufficient condition is also necessary, and offered this as an analysis of believing. (Collins 1987)
} 
will call this a belief fact. The third item is a belief property that a person might have-that of believing that the 504 stops at Garden. I'll call this a belief state. I will assume that propositions exist and can be true or false. What I want to consider is whether what I have called belief facts and states of believing can be true or false.

Is the property of believing that the 504 stops at Garden true or false? I suspect that putting it this way already makes clear that the answer is No. While that property is individuated by the proposition that the 504 stops at Garden, it is not generally true that a property inherits the properties of objects that individuate it. ${ }^{7}$ Consider the property of having a mass of $7 \mathrm{~kg}$. That property is individuated by the number 7 , but that property does not inherit the properties of the number 7 . That number is odd, but that mass is not odd. 7 is the successor of 6 and is a factor of 21. But that mass is not a successor of 6 nor a factor of 21. So the mass property does not share the number's arithmetic properties. So it is not in general true that a state individuated by an object inherits that object's properties. So the fact that belief properties are individuated by propositions does not entail that belief properties are themselves true or false. Indeed, it seems to me that belief properties do not have semantic properties, are not true or false, and do not bear semantic relations to other states of believing. This is not because they cannot have properties, for they can and do. It is rather, that they are not the right sort of entity to have semantic properties. To think they do is to confuse a property with the object that individuates it.

\footnotetext{
7 What follows echoes points made in (Matthews 2007) and (Stalnaker 1984), though neither author denies the idea that beliefs can be true or false. I develop the present points in more detail in (Hunter 2018a)
} 
What now about the facts or states of affairs that consist in Jones's believing that the 504 stops at Garden? Is that state of affairs true? I suspect that putting the question this way already makes clear that the answer is no. The fact that Jones believes that proposition-that fact or state of affairs - is not true or false. That fact is not about Garden Avenue. It has no semantic properties. And the reasons are basically the same as those for resisting saying that 3 is true. Consider a book that weighs $7 \mathrm{~kg}$. The fact that it weighs 7 $\mathrm{kg}$ is not odd or prime, and is not a factor of 21. That fact is not larger than 6 or smaller than 25 . The general point is that an exemplification of a property that is individuated by an object need not inherit the properties of that object.

One might consider it harmless to say that when a person is right in believing something then their belief is also true. But if our goal is to get clear on the nature of our mental lives then it is best to avoid the short-hands, especially if they encourage the homuncular fallacy of supposing that desires (and other mental states) have representational lives of their own. More seriously, though, these short-hands can distort the genuine explanatory problems we face in trying to understand the mind. Explaining how people but not trees or rocks can believe and desire is a real explanatory task, even though I think it is hard to make it precise. But the idea that we need to explain how states of believing and desiring get truth and satisfaction conditions is a pseudo-problem fed by an inattentive reliance on this sort of short-hand. Most importantly, though, these short-hands can make the person who believes and desires disappear from view. Returning our focus to the more fundamental idea that a person is right or wrong in believing something can help us put the believer back into view. ${ }^{8}$

8 The point is not restricted to 'right' and 'wrong'. Terms of epistemic praise and blame, such as 'reasonable', 'hasty', and 


\section{REFLECTION AND INFERENCE}

One who combined our first two assumptions, and so held that states of believing are particulars that are true or false, would naturally be attracted to our third assumption-that reasoning involves reflecting on and causally interacting with entities that have semantical relations to one another. There are two elements to this. One is that reasoning about how things are involves attending to representational states within oneself, as opposed to attending to objects and events in the world. The other is that making up or adjusting one's mind about how things are involves acting on entities that have an independent ontological and semantic existence. As Boyle neatly puts the idea: in reasoning "a person's agency can get no nearer to her beliefs than to touch them at their edges, so to speak." (Boyle, 2009, 121)

The first idea about reasoning is caricatured in the sketches Boyle and Hieronymi offer of the state view. They say that, on the view that believing is a mental state, reasoning and reflection are fundamentally like tending to the gears and chain on one's bike or storing a message on an answering machine. Matthew Chrisman seems to endorse this sort of view in the following.

What is involved in maintaining a system of beliefs? As the verb phrase suggests, it is dynamic rather than static. Maintaining something (e.g., a flowerbed) can be a reasonable answer to the question "What are you doing?" ... More specifically, as I am

'stubborn', apply primarily to believers and only in a misleading derivative sense to their states of belief. Likewise, terms such as 'satisfied', 'unsatisfied', and 'craven' apply in their primary use to people, and not to their states of desire. 
thinking of it, maintaining a system of beliefs involves examining and adjusting existing beliefs in light of newly acquired beliefs or propositions assumed to be true for various purposes (e.g., by raising or lowering one's credence in the old beliefs, or by reconceiving the inferential/evidential relations between beliefs if they seem to be in tension under various suppositions). It can also involve seeking out new beliefs-e.g., by investigation or deliberation-when one's system of beliefs leaves some important question open or some strongly held belief apparently unsupported by other beliefs." (Chrisman 2016, 16; italics added)

In this passage we find our three assumptions at work: states of believing as particulars in the same category as plants and bicycles (hence the plurals 'beliefs'); they have semantic properties (for they bear inferential relations to one another); and in reasoning a person reflects on and adjusts them as if they were geraniums in a flowerbed.

But the view that believing is a mental state entails none of this. Consider again the analogy between believing and owning. Jones can reflect and organize her possessions. But she does this, not by reflecting on and organizing her 'possessings', but by reflecting on and organizing her possessions. Her attention is directed at the objects she owns, the books and not on her ownership of them. We can say the same about reflection on what one believes. When Jones consider how she takes things to be, her attention is directed at what she believes not on her believing. On the standard view, propositions are the objects of belief, and so in reflection one attends to the propositions one believes. In other work, I have argued that the objects of belief are 
possibilities, ways that the world is or might have been. ${ }^{9}$ On this view, in reflection one attends to (putative) facts concerning which objects and events and processes have which properties. One can thus hold that believing is a mental state (and not an act or activity) while denying that reflection involves attending to internal representations.

Chrisman says that after examining one's system of beliefs one can 'adjust' them, by eliminating some, adding others, and even by changing the level of confidence we have in those we retain. This is the second element in this third assumption. It is the idea that reasoning involves acting on one's beliefs. Boyle and Hieronymi seem to agree that if believing is a mental states then making up one's mind would have to involve acting on state of believing in something like the way one might trim a plant or oil a chain. We could act on them only from the outside.

It is worth noting an assumption Boyle makes about the nature of inference. He assumes that if believing is a mental state then an inference would have to be an event that causes one to be in a state of believing (or that coincides with the initial onset of one's believing).

[1]f we exercise agential control over our beliefs, this must consist in our performing occurrent acts of judgment which give rise to new beliefs, or cause extant beliefs to be modified. Beliefs can at most "store" the results of such acts. So a person's agency can get no nearer to her beliefs than to touch them at their edges, so to speak. (Boyle, 2009, 121 ; italics added)

9 I develop this view in more detail in (Hunter 2018d). For a similar view, see (Richard 2013). 
This idea is certainly common in contemporary philosophy of mind. Among others, Boyle quotes Shoemaker.

[B] lieving something-having the standing belief that so and so is the case-is not an act. Judging, thought of as a mental occurrence rather than a standing state, is an act. (Shoemaker, 2009, 36)

As Boyle sees it, if believing is a mental state, and if judgment is a mental act, then judgment would have to be an act that causes or brings about believing, in something like the way maintaining a bicycle chain involves performing actions that, inter alia, cause its chain to be welloiled. Boyle sees this is a mistake that thinking of believing as itself an act or activity is meant to help us avoid.

Ryle (1959) famously ridiculed the idea that acts of judgment are events that cause or affect beliefs. If an act of judging were an event, he pointed out, then it would make sense to ask how long it took, whether it got interrupted, and whether it was slow or quick. Such temporal questions are sensible when applied to events, since events take time, but they seem absurd when applied to acts of judgment or inference. Judgment is simply not like that. Ryle never settled on a satisfactory account of judgment, and he was generally suspicious of mental acts.

But there is an alternative. According to it, an act of judging is a causing of a belief, rather than an event that causes a belief. Causings are not events, and so take no time. ${ }^{10}$ The temporal questions that make sense when

10 The idea that acts are causings and that causing are not events has a long pedigree, even though it remains a minority view. It is developed in (Bach 1980), who cites (Von Wright 1963) and (Chisholm 1964). Recently it is defended and developed by 
applied to events but seem inappropriate when applied to inference do not apply to causings. What is more, if a judging is a causing, then the person who judges is the cause, and what she causes is her own believing. In making up one's mind, one is not performing an act of judgment that has as a mere downstream effect that one believes something. Rather, judging that the 504 stops at Garden avenue just is making up one's mind that it does. And, after reflecting on one's evidence, confirming that it does just it keeping one's mind.

Here again, the analogy with ownership is illuminating. When Jones buys a book, her buying is not an event that has, as some downstream causal effect, that she owns it. Buying a book is a way to make it one's own, it is a way to own it. And when she gives it to her brother, her giving is not an act that has, as some downstream causal effect, that she no longer owns it. Giving it to her brother just is ceasing to own it. And in buying or giving it away, Jones herself is the cause, she is responsible for owning and ceasing to own it. The same can be said about believing. When, after reflecting on how things are, Jones judges that the 504 stops at Howard Park (or when she reconfirms that it does), she is not agent of an act that has, as a downstream effect, that she believes (or continues to believe) that it does. Rather, she herself is the cause of her believing (or continuing to believe it). In making up or keeping her mind, she makes the believing her own. She owns it.

(Alvarez and Hyman 1998) and (Hyman 2015). The idea that a person can be a cause also has a long pedigree. It is developed in different ways by (Strawson 1992), (Thomson 1977), (Alvarez and Hyman 1998) and (Hyman 2015). I know of no one who has developed the idea that making a judgment is causing oneself to believe. I develop it in detail in (Hunter 2018c) 


\section{ARE BELIEF STATES CAUSES?}

Our first three assumptions fit naturally with the fourth, that states of believing have a causal life of their own. This idea is explicit in Hieronymi's caricature of the state view. If believing were a mental state, she says, then a belief would be like a message on her answering machine. Once stored, the message broadcasts without her help. The machine would do it, Hieronymi says it, "on [her] behalf." A person's state of believing, once stored, would move her arms and legs in something like the way her heart pumps her blood, without her own agency being involved. The believer would be effectively passive when acting on what she believes. To avoid this passivity, Hieronymi holds that believing is itself an activity, something the agent actively does.

But this response, it seems to me, misunderstands what it is for a person to act on a belief. In the literature, there are two standard ways to think of a belief state's causal life, both of which we should resist. First, one might take mental states to be themselves causes. Or one might take believing something to be having a causal power. We should resist both ideas. Believing is neither a cause nor a causal power. Instead, for a person to believe something is for her to be in a certain position from which to exercise her causal powers.

David Armstrong claimed that "the concept of a mental state essentially involves, and is exhausted by, the concept of a state that is apt to be the cause of certain effects or apt to be the effect of certain causes." (Armstrong 1981). I share Hieronymi's sense that this is an absurd picture of the role believing plays in action. ${ }^{11}$ But there is nothing in the notion of believing that entails that a state of believing is a cause. (It was not Cromwell's sense of humour that caused

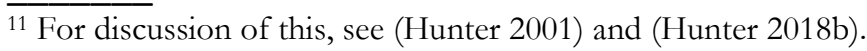


him to laugh - it was the joke.) If we abandon the idea that there are token beliefs, this gets us a good way towards seeing that beliefs and desires need not be considered causes. But it is just as important to notice that other perfectly familiar states are not, as part of their very nature, causes. Suppose Jones can play the piano, and so has that ability. Her having that ability is her being in a certain state. And suppose she plays 'Hey Jude'. Her ability did not cause her to play that song. Nor did it cause her playing of it. In playing the song, she exercised her ability to play it. Of course, that Jones has that ability makes a difference to what she can do: having it just is being able to do something that one who lacks the ability is not able to do. And the better she is at playing the piano, the better she will play. So her having that ability makes a difference to what she can do. We can say all of this while denying that the ability itself was the cause and while insisting that having an ability is being in a certain state. So it is not in general true that states are causes of their exercises.

Instead of Armstrong's idea that states of believing are themselves causes, one might instead think that having a belief is a matter of having a certain causal power. A natural model would be fragility. Once I make my vase fragile by cooling it, the fragility all by itself can make the vase shatter when it hits the ground. If we model states of believing on fragility, one might think that once a person has formed a belief, then she could sit back and watch as it does things on her behalf. This idea that beliefs are causal dispositions is widespread. ${ }^{12}$ But it does not follow from the idea that believing is a mental state. Earlier I said that we might think of believing as a rational ability. It is common to develop

12 It is notably encouraged by (Ryle 1959) who called them dispositions, and was labelled a behaviourist on account of it, even though he took pains to note that believing is in crucial ways unlike a natural tendency (e.g., acidic) or liability (e.g., solubility). 
this idea by analogy with physical dispositions like being acidic or being soluble. But we should resist this analogy too.

To see this, we need to distinguish having a causal power from being positioned to exercise it. I take it that a causal power is a power to undergo or bring about a certain change, and that causal powers are individuated by the associated change. Being soluble is a liability to dissolve (i.e., undergo dissolution) in liquids. Being an acid is an ability to make certain substances dissolve. Being able to play piano is an ability to perform musical compositions on a piano. A thing can have a power without being in position to exercise it. A cube of salt won't dissolve unless it is in water, a volume of acid won't dissolve anything while safely stored, and a pianist won't play piano unless she is at one. Being in position to exercise a causal power is not itself a causal power. It is not that the cube of salt gained a new power when placed in the warm water. Rather, it became positioned to exercise the power it already had.

It is helpful to compare this to being in a certain geographical location. When Marco is in London, he can walk along Regent street. But it is not that he has some ability in London that he lacks when at home in Campinas. In both places he is able to walk. The difference is that when he is in London he can exercise that ability on Regent street. Being able to exercise an ability on Regent street is not itself a new ability or power: it is, rather, being in a certain position to exercise an ability. This nuance is obscured by the promiscuity of the English word 'can' which is used in ascribing both an ability and an opportunity. We say that Marco can walk on Regent street when in London but not when in Campinas. But this marks a difference in opportunity not in ability. 
We can think of believing on the model of being in a certain location. ${ }^{13}$ I earlier noted the traditional idea that to know that $\mathrm{p}$ is to be able to do, feel or think something in light of the fact that $p$, and I suggested we think of believing as being able to do, feel or think something in light of a (putative) fact. But care is needed here. It is tempting to think that in coming to know something one gains an ability - in the sense of a causal power - that one previously lacked: an ability to do, think or feel something in light of the fact or possibility that p. But we need not think of it this way. We can think of it as like changing one's location. Suppose Simon does not believe that the 504 stops at Garden. The difference between Jones and Simon is not a difference in whether they can walk to Garden avenue, since both may have that ability. The difference is that Jones but not Simon can walk to Garden because the 504 stops there. Only Jones is positioned to exercise that shared ability in light of that fact. That's what knowing and believing make possible. In this respect, a change in belief is like moving from Campinas to London: it is a changes in one's position in the space of reasons.

Let me try to summarise this discussion. I began by noting that contemporary philosophy of mind has tended to make the believer disappear from view. Some, like Matt Boyle and Pamela Hieronymi, have responded by replacing the idea that believing is a mental state with the idea that it is an act or an activity. I have argued that this response rests on a failure to fully critique contemporary accounts of the nature of mental states. I identified four assumptions they share with contemporary accounts: (i) states of believing are

\footnotetext{
13 In conversation, Charles Travis once suggested that believing is a disposition in the sense in which Napoleon has his armies in a certain disposition on the hillside. And the Oxford English Dictionary offers as a primary use 'The plan shows the disposition of the rooms'.
} 
particulars; (ii) with semantic properties; (iii) that we attend to in reflection and act on in inference; and (iv) with a rich causal life of their own. Together, these assumptions leave no room for the believer in an account of believing. She is pictured as a mere bystander, a container for entities that represent and act on her behalf and which she can control only as an observer, from the outside. But these assumptions are not entailed by the idea that believing is a mental state. Careful reflection on other kinds of states, such as ownership, musical abilities, and spatial location, can help us see how to put the believer back in the heart of our account of believing. They can show reveal how believers can be responsible for representing the world, for making or keeping up their mind about it, and when acting on what they believe. ${ }^{14}$

\section{REFERENCES}

Alvarez, $M$ and Hyman, J. Agents and their acts. Philosophy, 73, 219-245, 1998.

Armstrong, D. The nature of mind. Cornell: Cornell University Press, 1981.

Austin, J.L. Philosophical papers. Oxford: Oxford University Press, 1979.

BACH, K. Actions are not events. Mind, 89(353), 114-120, 1980.

$14 \mathrm{I}$ am indebted to the participants at the 2018 workshop in Campinas, Brazil for generous and constructive feedback. My thoughts here are deeply influenced by conversations with (and encouragement by) Eric Marcus, Matt Boyle, David Horst, Sergio Tenenbaum and others. 
Boyle, M. Active Belief. Canadian Journal of Philosophy, Supplementary volume 35, 119-147, 2009.

"Making up your mind" and the activity of reason. Philosopher's Imprint, 11(17), 1-24, 2011.

Braddon-Mitchell, D and Jackson, F. Philosophy of Mind and Cognition. Malden: Blackwell Publishers, 1996.

ChISHOLM, R. The descriptive element in the concept of action. Journal of Philosophy 61, 613-625, 1964.

CHRISMAN, M. Epistemic normativity and cognitive agency. Noûs doi 10.1111/nous.12184, 2016.

Collins, A. The Nature of Mental Things. Notre Dame, IN: Notre Dame University Press, 1988.

Hieronymi, P. Believing at Will. Canadian Journal of Philosophy, supplementary volume 35, 135-187, 2009.

HunTER, D. 2018a. Are beliefs true? Ms. 2018b. Understanding disordered belief. Ms. 2018c. Inference as a mental act. Ms. 2018d. The objects of belief. Ms.

Guidance and belief. Canadian Journal of Philosophy, supplementary volume 35, 63-90, 2009.

Belief and self-consciousness. International Journal of Philosophical Studies, 16(5), 673-693, 2008.

Mind-brain identity and the nature of states. Australasian Journal of Philosophy, 79(3), 366-376, 2001.

HyMAn, J. How knowledge works. The Philosophical Quarterly, 49(7), 433-451, 1999.

Action, Knowledge and Will. Oxford: Oxford University Press, 2015. 
Kenny, A. The Metaphysics of Mind. Oxford: Oxford University Press, 1989.

KIM, J. Philosophy of mind. Boulder: Westview, 1996.

MARCUS, E. Why there are no token states. Journal of Philosophical Research, 34, 215-241, 2009.

Events, sortals, and the mind-body problem. Synthese, 150, 99-129, 2006.

MARCus, E. Rational Causation. Cambridge, MA: Harvard University Press, 2014.

Matthews, R. The Measure of Mind. Oxford: Oxford University Press, 2007.

RICHARD, M. What are propositions?' Canadian Journal of Philosophy, 43(5-6), 702-719, 2013.

RYLE, G. The Concept of Mind. New York: Barnes \& Noble, 1949.

SETIYA, K. Believing at Will. Midwest Studies in Philosophy, 32, 36-52, 2008.

SHOEMAKER, S. Self-intimation and second order belief. Erkentnnis, 71, 35-51, 1989.

STALNAKER, R. Inquiry. Cambridge, MA: MIT Press, 1984.

STEWARD, H. The Ontology of Mind. Oxford: Oxford University Press, 1997.

STICH, S. From Folk Psychology to Cognitive Science: the case against belief. Cambridge, MA: MIT Press, 1985.

STrawson, P. Analysis and Metaphysics. Oxford: Oxford University Press, 1992.

Thomson, J. Acts and other Events. Ithaca, NY.: Cornell University Press, 1977. 
Velleman, J. The possibility of practical reasoning. New York: Oxford University Press, 2000.

Practical reflection. Stanford, CA: CSLI Publications, 2007.

VON Wright, G. H. On so-called practical inference. In J. Raz (Ed.) Practical reasoning (pp. 1-17), Oxford: Oxford University Press, 1978.

Williams, B. Deciding to believe. In Problems of the Self, Cambridge: Cambridge University Press, 136-51, 1973.

VENDLER, Z. Res Cogitans. Ithaca: Cornell University Press, 1972.

$(\mathrm{cc})$ EY 